\title{
Contra o silêncio racial nos dados universitários: desafios e propostas acerca da Lei de Cotas ${ }^{1}$
}

\author{
Adriano Souza Senkevics ${ }^{2}$
}

\section{Resumo}

0 debate em torno das desigualdades raciais no acesso à educação superior tem ensejado, desde a última década, a adoção de políticas de ação afirmativa voltadas à correção de disparidades históricas, a exemplo da Lei de Cotas (Lei nº 12.711/2012). Porém, a despeito de sua importância, esta ainda carece de mecanismos consolidados que possibilitem seu monitoramento e avaliação, tendo em vista que um dos levantamentos potencialmente mais úteis para tal operação - como o Censo da Educação Superior (CES) - padece de elevados índices de não declaração racial, em razão da subnotificação do quesito cor/raça por parte das Instituições Federais de Educação Superior (IFES). Com o objetivo de propor soluções para esse problema, esta pesquisa lançou mão da base de dados dos ingressantes dos cursos de graduação das IFES no CES, entre 2012 e 2015, para, a partir de cruzamentos com a base de dados do Exame Nacional do Ensino Médio (ENEM), rastrear a informação de cor/raça autodeclarada pelos mesmos indivíduos quando de sua inscrição no exame e, assim, tomar suas respectivas declarações raciais no ENEM como forma de aumentar a taxa de declaração racial no Censo. Entre os ingressantes de 2015, esse procedimento elevou a referida taxa de 75,9\% para 96,4\%. Ademais, analisamos os incrementos obtidos segundo as combinações formadas por trincas de Instituição-Curso-Turno, entendidas como a unidade de referência da Lei de Cotas e concluímos que tal operação, além de introduzir poucos vieses na composição racial dos ingressantes, apresenta-se como uma estratégia válida para potencializar o acompanhamento da referida legislação enquanto persistirem elevadas taxas de subnotificação racial.

\section{Palavras-chave}

Ação afirmativa - Educação superior - Relações étnico-raciais - Universidades federais.

1- Agradecemos a Adolfo Samuel de Oliveira, Lucas Rocha Soares de Assis, Rachel Pereira Rabelo e Ursula Mattioli Mello.

2- Instituto Nacional de Estudos e Pesquisas Educacionais Anísio Teixeira, Brasília, DF, Brasil. Contato: adriano.senkevics@inep.gov.br 


\title{
Against racial silence in university data: challenges and proposals about the Federal Law of Quotas ${ }^{1}$
}

\author{
Adriano Souza Senkevics²
}

\section{Abstract}

Discussions on racial inequalities in the access to higher education have promoted, since the last decade, the adoption of affirmative action policies aimed at correcting historical disparities, such as the Federal Law of Quotas (Act No. 12.711/2012). However, in spite of its importance, this policy still lacks mechanisms for monitoring and evaluation, given that one of the potentially most useful surveys for that - the Census of Higher Education (CES, in Portuguese) - presents high rates of non-racial statement, due to the missing values of the color/race item reported by the Federal Higher Education Institutions (IFES, in Portuguese). Intending to enhance the monitoring process of this legislation, this study made use of the incoming undergraduate students databases of the IFES at the CES, from 2012 through 2015, in order to, by merging them with the National High School Exam (ENEM, in Portuguese) datasets, search for the color/race information self-ascribed by the same individuals when they signed up for the exam, and thus take their respective racial statements in ENEM with the purpose of increasing the racial statement rate in the Census. Among 2015 students, this procedure has increased racial statement from 75.9 percent to 96.4 percent. In addition, I analyze the results obtained according to the combinations formed by Institution-Course-Shift, considered as the reference unit of the Law of Quotas, and conclusion is that this operation, not only adds up few biases in the racial composition of the students but it can also be considered a valid strategy to enhance the monitoring of such policy as long as high rates of racial underreporting persist.

\section{Keywords}

Affirmative action - Higher education - Ethnic/racial relations - Federal universities.

A educação superior brasileira é palco de persistentes desigualdades raciais que comprometem, até os dias de hoje, a garantia do direito pleno à educação para a população. De acordo com Lima e Prates (2015, p. 175), é entre o público de 18 a 24 anos que "as taxas de escolarização líquida são mais baixas e as desigualdades raciais ainda mais expressivas”. Ribeiro e Schlegel (2015) apontam que, entre 1980 e 2010, negros não constituíram maioria entre os formados de nenhum dos 25 importantes cursos de graduação analisados. Mesmo diante desse panorama, Artes e Ricoldi (2015) pontuam que, entre 2000 e 2010, houve um crescimento significativo no acesso à graduação (116\%), tendo ocorrido variações expressivas em função da cor ou raça dos estudantes - a presença 
de negros nos cursos de graduação, por exemplo, aumentou 291\% (ou 278\% para pardos e 384\% para pretos) no período considerado.

Com o intuito de reverter esse quadro histórico de desigualdades, tem sido proposta, desde as últimas décadas, a instituição de políticas de ação afırmativa ${ }^{3}$, encampadas principalmente por setores da militância antirracista com o apoio de diversos movimentos sociais, de entidades acadêmicas e de gestores públicos (Cf. MOEHLECKE, 2004; SANTOS, 2005).

De fato, os esforços empreendidos nas últimas décadas para institucionalizar ações que visem à superação das desigualdades raciais ensejou, por parte do Estado, a promulgação de marcos legais como o Plano Nacional de Promoção da Igualdade Racial (Decreto $\mathrm{n}^{\circ}$ 6.872, de 4 de junho de 2009) e o Estatuto da Igualdade Racial (Lei $\mathrm{n}^{\circ} 12.288$, de 20 de julho de 2010) - ambos explicitam a importância de se implementar e acompanhar a execução de políticas de ação afırmativa, prevendo, a exemplo do primeiro, a inclusão do quesito cor/raça em formulários de coleta de dados discentes em todos os níveis de ensino público e privado.

Uma das políticas de ação afırmativa mais relevantes no Brasil da atualidade é a reserva de vagas para o acesso ao ensino superior ou, como são comumente conhecidas, as políticas de cotas étnico-raciais. Instituídas no âmbito das universidades desde a década passada, e obedecendo a uma miríade de regras e critérios que variavam institucionalmente (Cf. HERINGER, 2010; DAFLON; FERES JÚNIOR; CAMPOS, 2013), só recentemente a Lei de Cotas (Lei $\mathrm{n}^{\circ}$ 12.711, de 29 de agosto de 2012) foi promulgada no país, representando um marco nacional na definição de parâmetros inclusivos para o acesso às Instituições Federais de Educação Superior (IFES) e aos Institutos Federais de Ensino Técnico de Nível Médio vinculados ao Ministério da Educação.

Com relação ao nível superior, a legislação prevê que 50\% das vagas em todos os cursos e turnos das IFES devam se destinar aos estudantes que cursaram o ensino médio na rede pública de ensino ${ }^{4}$. Em seguida, estabelece uma segunda reserva de vagas, dentro desse primeiro contingente, voltada para outras duas condições: uma proporção mínima de 50\% de estudantes oriundos de famílias cuja renda per capita é igual ou inferior a 1,5 salário-mínimo; e uma proporção de autodeclarados pretos, pardos e indígenas que, juntos, devem ser equivalentes à soma dessas populações na Unidade da Federação (UF) onde se encontra a referida instituição ${ }^{5}$.

Dessa forma, a Lei de Cotas pode ser considerada abrangente, por mirar diferentes expressões das desigualdades sociais, e potencialmente importante para reduzir a estratificação social no acesso à educação. No entanto, a despeito de sua relevância, essa legislação ainda carece de efetivos mecanismos que possibilitem seu monitoramento e avaliação (Cf. LAZAR0, 2016, p. 153). Exemplo disso são as dificuldades ainda existentes

\footnotetext{
3- Por ações afirmativas, entendem-se medidas temporárias, focalizadas e compensatórias; um conjunto heterogêneo de políticas e programas, adotadas temporariamente, com o intuito de mitigar os efeitos de uma discriminação historicamente existente sobre grupos vulneráveis (PIOVESAN, 2005). Para uma discussão mais profunda, indicamos Vieira (2016).

4- 0 Decreto $n^{0} 7.824 / 2012$ igualmente habilita para a concorrência às vagas reservadas os estudantes que tenham concluído 0 ensino médio com base em exames de certificação nacionais ou estaduais.

5 - Acrescenta-se que a Lei nº 13.409/2016 adicionou aos critérios para delimitação dos beneficiários um percentual de pessoas com deficiência similar ao da UF de referência. Porém, em razão de nossa ênfase sobre as desigualdades socioeconômicas e étnico-raciais, não abordaremos esse tópico neste texto.
} 
para a composição de um amplo retrato do perfil racial dos estudantes em nível superior, como se esperaria obter por meio do Censo da Educação Superior (CES), levantamento censitário de matrículas, cursos, funções docentes e instituições em nível superior realizado anualmente pelo Instituto Nacional de Estudos e Pesquisas Educacionais Anísio Teixeira (INEP).

De acordo com Senkevics, Machado e Oliveira (2016), informações relacionadas à cor/ raça estão presentes no CES, como um campo específico para os formulários de estudantes e docentes, desde 2009. Os itens seguem o padrão utilizado pelo Instituto Brasileiro de Geografia e Estatística (IBGE) ${ }^{6}$ - branca, preta, parda, amarela e indígena - com a adição de duas opções que expressam a ausência de informação racial: "Não declarada" e "Não dispõe da informação". Tal padrão foi mantido sem alterações entre 2009 e 2013; a partir de 2014, por sua vez, a categoria "Não declarada" passou a ser apresentada como "Aluno não quis declarar a cor/raça”. Além dessas informações, é importante mencionar que a instrução para o preenchimento desse campo, de caráter obrigatório, é a autodeclaração, a qual deve ser obtida pela instituição e inserida pelo responsável institucional em um sistema virtual.

Ao analisarmos o percentual de respostas às opções não declaratórias no CES, para estudantes de graduação das IFES, obtemos o Gráfico 1. É possível perceber uma tendência de decréscimo na não declaração total, a qual reduziu de 59,2\%, em 2009, para 29,2\%, em 2015. Essa queda de 30 pontos percentuais (p.p.) representa um incremento na taxa de declaração racial e, portanto, um avanço na obtenção de informações a respeito da composição étnico-racial dos estudantes nesse nível de ensino.

Gráfico 1 - Percentual de respostas às opções de não declaração racial entre estudantes de graduação das IFES - 2009-2015

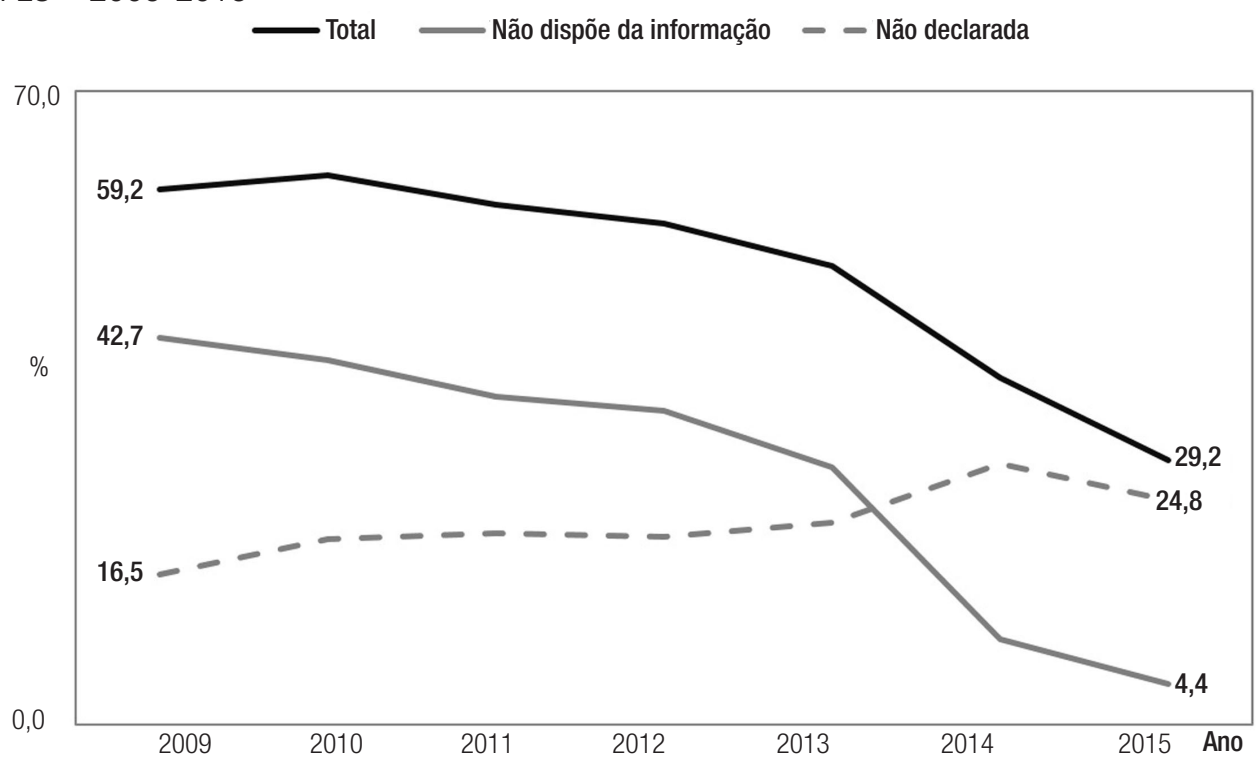

Fonte: CES (INEP). Elaboração própria.

6- Para conhecer um histórico do sistema de classificação racial no Brasil, ver Oliveira (2002), Petruccelli (2012) e Piza e Rosemberg (2012). 
Essa redução no total de não declaração se deve essencialmente a uma queda acentuada (de 38,3 p.p.) no percentual de respostas à opção "Não dispõe da informação", que alcançou o patamar mínimo de 4,4\% das matrículas. Contudo, há de se notar o acréscimo no percentual de respostas "Não declarada" ao longo dos anos, o qual partiu de 16,5\%, em 2009, para 24,8\%, em 2015. Em parte, essa compensação, deve ter acontecido pelo fato de o INEP ter continuamente pressionado as instituições a não preencherem a opção "Não dispõe da informação", tendo em vista que essa categoria se contrapõe à obrigatoriedade de preenchimento do quesito cor/raça.

Desde 2014, por exemplo, o INEP impediu que as instituições marcassem a opção "Não dispõe da informação" para os ingressantes, razão possivelmente por trás da queda acentuada no percentual de respostas a essa opção no último ano. Porém, parte dessa redução parece ter migrado para a opção "Não declarada", como uma sugestão de que, na ausência da informação racial, a instituição tende a alegar que o estudante não declarou sua cor/raça mesmo que, de fato, tal quesito não tenha sido sequer apresentado.

Como decorrência da ausência de uma ampla cobertura do perfil racial do alunado em nível superior, o monitoramento de políticas públicas como a Lei $n^{\circ}$ 12.711/2012 é comprometido. Ao mesmo tempo, sabe-se que o Exame Nacional do Ensino Médio (ENEM), o qual tem se apresentado desde os últimos anos como o principal mecanismo de seleção de ingressantes para o nível superior público por meio do Sistema de Seleção Unificada (SISU), exibe taxas de declaração racial bastante elevadas (SENKEVICS; MACHADO; OLIVEIRA, 2016), além de apresentar as mesmas cinco categorias de cor/raça empregadas pelo CES com a adição de uma categoria de não declaração ("Não declarado"), fato que nos levou a desenvolver a proposta discutida neste estudo.

Criado em 1998 com a finalidade de avaliar o desempenho individual dos concluintes do ensino médio, e, desde 2009, reformulado para o formato que se conhece atualmente, o ENEM tem adquirido novas finalidades e uma crescente importância no cenário educacional brasileiro. Desde o seu surgimento, o exame é realizado anualmente e obtém dados de cor/ raça de seus inscritos. Até 2009, essa coleta acontecia por meio do questionário, entregue ao candidato no ato da inscrição. De 2010 em diante, passou-se a adotar o sistema de inscrição em ambiente virtual, que tornou obrigatório o preenchimento do quesito cor/ raça, apresentado nas telas iniciais do sistema como condição para efetivar a inscrição do candidato. Não havendo mais a possibilidade de não preenchimento do quesito cor/raça, análises acerca da perda de informação racial no ENEM limitaram-se ao fenômeno da não declaração deliberadamente assinalada pelos respondentes - em tempo, percentuais bastante diminutos de candidatos optaram por não declarar nenhum pertencimento racial, em valores que caíram de 3,3\%, em 2010, para 1,6\%, quatro anos depois.

Em vista das considerações apresentadas, e com a finalidade de contribuir para o aperfeiçoamento dos mecanismos de monitoramento da Lei de Cotas, esta pesquisa objetivou analisar o fenômeno dos elevados índices de não declaração racial no Censo da Educação Superior para, em seguida, propor formas de aprimoramento da abrangência e qualidade desses dados. Para tanto, este texto ocupar-se-á de investigar as potencialidades de se acrescentar informações acerca da cor/raça de ingressantes das IFES, no CES, a partir do cruzamento com as bases de dados do ENEM, tomando suas respectivas declarações raciais no segundo como maneira de incrementar as taxas de declaração racial no primeiro. 


\section{Procedimentos metodológicos}

Esta é uma pesquisa de natureza quantitativa, que se baseou essencialmente no tratamento e análise de diferentes bases de dados do INEP: aquelas relativas aos estudantes no Censo da Educação Superior (CES) e aquelas referentes aos inscritos no Exame Nacional do Ensino Médio (ENEM). De acordo com o Quadro 1, nota-se que ambos levantamentos obtêm dados de cor/raça por meio de formulários eletrônicos - o primeiro deles, pelo sistema Censup (Censo da Educação Superior); o segundo, pela página inicial do formulário de inscrição no exame. Quanto ao método de declaração racial, também não há diferenças: ambos são orientados para serem informados de acordo com a autodeclaração do respondente ${ }^{7}$. A principal diferença metodológica entre o CES e o ENEM reside na forma de preenchimento do dado de cor/raça. Enquanto o primeiro é preenchido por terceiros, que lançam no sistema virtual os dados obtidos de estudantes e docentes, o segundo é respondido pelo próprio indivíduo, que indica seu pertencimento racial quando da inscrição no exame.

Quadro 1 - Classificação do CES e do ENEM quanto ao tipo de instrumento, declaração e preenchimento do quesito cor/raça.

\begin{tabular}{|c|c|c|c|}
\hline Pesquisa & Instrumento & Declaração & Preenchimento \\
\hline Censo da Educação Superior (CES) & Formulário (Censup) & Autodeclaração & Heteropreenchimento \\
\hline Exame Nacional do Ensino Médio (ENEM) & Formulário (Sistema de Inscrição) & Autodeclaração & Autopreenchimento \\
\hline
\end{tabular}

Fonte: INEP. Adaptado de Senkevics, Machado e Oliveira (2016).

Para elaborar a base de dados dos ingressantes dos cursos de graduação das IFES ${ }^{8}$ no CES, somada ao cruzamento dos dados de diferentes edições do ENEM, lançamos mão dos seguintes passos: (1) em primeiro lugar, preparamos quatro bases distintas de ingressantes do CES, uma para cada ano (de 2012 a 2015), com informações sobre características individuais dos estudantes (sexo, data de nascimento e cor/raça) e dos cursos de graduação por eles frequentados; (2) em seguida, preparamos cinco bases distintas do ENEM, uma para cada edição (de 2010 a 2014), também com informações sobre características individuais dos inscritos; (3) finalmente, utilizamos uma chave de ligação ${ }^{9}$ para cruzar as bases de dados, permitindo que se identificassem os mesmos estudantes a fim de mesclar informações do CES e do ENEM.

Restringimos nossas análises a partir do CES 2012, pois a sanção e vigência da Lei de Cotas data desse mesmo ano - entendemos, portanto, que 2012 é a linha de base

7- Para uma leitura acerca dos métodos de declaração racial, recomendamos Osorio (2003).

8- Mesmo que não contemplados pela lei em voga, incluímos nas análises o Instituto Tecnológico da Aeronáutica, o Instituto Militar de Engenharia e a Escola Nacional de Ciências Estatísticas, a fim de contemplar a totalidade das IFES, vinculadas ou não ao Ministério da Educação - MEC.

9- Como chave de ligação foi utilizado o Cadastro de Pessoa Física (CPF) de cada estudante. 
para o nosso estudo -, e estendemo-la até 2015 por ser o período mais recente para o qual existiam dados publicados no momento de desenvolvimento da pesquisa. A partir da chave de ligação adotada, foram rastreados os mesmos indivíduos nas bases de dados das três edições do ENEM imediatamente anteriores a cada uma das edições do CES - por exemplo, para os ingressantes de 2015, seus dados foram cruzados com as edições de 2014, 2013 e 2012 do ENEM, nessa ordem. Desse modo, ao recorrer a mais de uma edição do exame, procuramos localizar a maior quantidade possível de ingressantes das IFES no contingente de inscritos no ENEM. Para tanto, chamaremos de ENEM 1 a edição do ENEM imediatamente anterior à determinada edição do CES - seguindo nosso exemplo, o ENEM 1 do CES 2015 é o ENEM 2014; de ENEM 2, a segunda edição imediatamente anterior ao referido CES; e de ENEM 3, quando for o caso, a terceira edição imediatamente anterior ${ }^{10}$ (Quadro 2).

Quadro 2 - Esquema do cruzamento das bases de dados do CES e do ENEM.

\begin{tabular}{|c|c|c|c|c|c|}
\hline Base de dados & ENEM 2014 & ENEM 2013 & ENEM 2012 & ENEM 2011 & ENEM 2010 \\
\hline CES 2012 & & & & ENEM 1 & ENEM 2 \\
\hline CES 2013 & & & ENEM 1 & ENEM 2 & ENEM 3 \\
\hline CES 2014 & & ENEM 1 & ENEM 2 & ENEM 3 & \\
\hline CES 2015 & ENEM 1 & ENEM 2 & ENEM 3 & & \\
\hline
\end{tabular}

Elaboração própria.

Com essas bases em mãos, que mesclam informações de ingressantes das IFES com dados dos mesmos indivíduos quando de suas inscrições no ENEM, partimos para as etapas de análise. Antes de executar a complementação das informações raciais no CES a partir do ENEM, verificamos o grau de concordância e discordância na declaração racial dos mesmos indivíduos entre as duas bases de dados, com o intuito de conhecer as eventuais divergências na classificação racial entre os dois levantamentos e, assim, estimar possíveis vieses que a almejada complementação de dados traria para o Censo.

Em seguida, considerando as elevadas taxas de não declaração racial no CES, realizamos a complementação de dados raciais via ENEM, com o intuito de avaliar o quanto de informação sobre cor/raça poderia ser acrescentada se tomássemos, no caso dos ingressantes sem declaração racial, a cor/raça que os indivíduos atribuíram a si nas edições do exame. Para tanto, agregamos as opções "Não dispõe da informação" e "Não declarada"/“Aluno não quis declarar a cor/raça” do CES em uma única categoria que chamamos de "Não declaração (total)”. Em seguida, realizamos a complementação de dados do CES via ENEM obedecendo à seguinte regra: no caso de o ingressante já ter uma cor/raça declarada no Censo, mantivemos esta, por entendermos que se trata

10- Trabalhamos exclusivamente com as edições do ENEM a partir de 2010, em razão de ter sido este 0 ano em que a obtenção dos dados de cor/raça passou a acontecer por meio do sistema de inscrição, com índices bastante baixos de não declaração (Cf. SENKEVICS; MACHADO; OLIVEIRA, 2016). 
da informação mais recente, obtida no âmbito do próprio levantamento de dados que buscamos aprimorar; porém, caso o ingressante não tivesse uma cor/raça declarada no Censo, suprimos essa falta com a cor/raça declarada nas edições anteriores do ENEM, priorizando as mais recentes, isto é, mais próximas do ano de ingresso do estudante.

Para finalizar esta seção, é essencial mencionar os trâmites necessários para se trabalhar com dados protegidos. Por termos utilizado uma informação pessoal sensível, foi solicitada a autorização do INEP no âmbito da Portaria n ${ }^{\circ}$ 467, de 19 de setembro de $2014^{11}$, concedida aos pesquisadores em 26 de fevereiro de 2016, a qual permite o uso de informações pessoais para estudos com fins científicos e assevera que os resultados divulgados não identifiquem os sujeitos e tampouco individualizem as análises. Nesse sentido, é importante frisar que os resultados aqui apresentados estão em conformidade com os preceitos legais e éticos da referida norma, na medida em que são apresentados de forma agregada, preservando o sigilo das informações pessoais e a identificação dos respondentes.

\section{Declaração racial e ingressantes das IFES}

0 número de ingressantes nos cursos de graduação das IFES variou de 334 mil em 2012 para 336 mil em 2015, de acordo com o Censo da Educação Superior (Tabela 1).

Tabela 1 - Quantidade (n) e percentual (\%) de matrículas de ingressantes dos cursos de graduação das IFES, segundo a cor/raça - 2012-2015.

\begin{tabular}{|c|c|c|c|c|c|c|c|c|}
\hline \multirow{2}{*}{ Cor/Raça } & \multicolumn{2}{|c|}{2012} & \multicolumn{2}{|c|}{2013} & \multicolumn{2}{|c|}{2014} & \multicolumn{2}{|c|}{2015} \\
\hline & $\mathrm{n}$ & $\%$ & $\mathrm{n}$ & $\%$ & $\mathrm{n}$ & $\%$ & $\mathrm{n}$ & $\%$ \\
\hline Branca & 71.710 & $21,5 \%$ & 77.033 & $23,7 \%$ & 103.575 & $29,8 \%$ & 116.818 & $34,8 \%$ \\
\hline Preta & 18.617 & $5,6 \%$ & 19.018 & $5,8 \%$ & 22.901 & $6,6 \%$ & 28.521 & $8,5 \%$ \\
\hline Parda & 47.413 & $14,2 \%$ & 57.211 & $17,6 \%$ & 97.228 & $28,0 \%$ & 102.746 & $30,6 \%$ \\
\hline Amarela & 2.570 & $0,8 \%$ & 3.264 & $1,0 \%$ & 3.451 & $1,0 \%$ & 4.403 & $1,3 \%$ \\
\hline Indígena & 712 & $0,2 \%$ & 822 & $0,3 \%$ & 1.642 & $0,5 \%$ & 2.540 & $0,8 \%$ \\
\hline Não declaração (total) & 193.190 & $57,8 \%$ & 167.919 & $51,6 \%$ & 118.194 & $34,1 \%$ & 81.065 & $24,1 \%$ \\
\hline Total & 334.212 & $100,0 \%$ & 325.267 & $100,0 \%$ & 346.991 & $100,0 \%$ & 336.093 & $100,0 \%$ \\
\hline
\end{tabular}

Fonte: CES (INEP). Elaboração própria.

Vê-se que, fora os "não declarados", brancos e pardos compõem os grupos mais expressivos entre os ingressantes dos cursos de graduação das IFES, em valores que somam dois terços das matrículas no ano de 2015. Em razão da diminuição da não declaração

11- Na atualidade, a referida portaria foi substituída pela Portaria $n^{\circ} 465$, de 31 de maio de 2017, que cria o Serviço de Acesso a Dados Protegidos (Sedap) do INEP e mantém as funcionalidades da norma até então vigente. 
racial ao longo dos anos, todos os demais grupos de cor/raça têm testemunhado aumentos absolutos e relativos no conjunto dos ingressantes. Em que pesem esses aprimoramentos, é patente que o perfil racial de parcela significativa dos estudantes resta desconhecido em virtude da persistência de elevados índices de não declaração racial, fato que compromete o emprego desse levantamento para fins de pesquisas sobre desigualdades raciais no ensino superior (Cf. ARTES; RICOLDI, 2015; ARTES, 2016; HONORATO, 2015).

Para iniciar as análises do cruzamento entre as bases de dados, na Tabela 2 apresentamos a quantidade e o percentual de matrículas de ingressantes de 2012 a 2015 que conseguimos rastrear nas respectivas bases de dados do ENEM. De imediato, é possível observar que, independentemente da edição do ENEM, os maiores percentuais de indivíduos encontrados a partir do cruzamento de bases de dados ocorrem no CES 2015. Isso pode ser facilmente explicado pelo fato de o ENEM estar se tornando cada vez mais importante para a seleção de estudantes ao ensino superior, de modo que o crescimento da adesão das IFES ao SISU, ao longo dos anos, tem induzido um número maior de candidatos a prestarem o exame.

Tabela 2 - Quantidade e percentual de matrículas de ingressantes dos cursos de graduação das IFES localizadas no ENEM a partir dos cruzamentos de bases de dados - 2012-2015.

\begin{tabular}{|c|c|c|c|c|c|}
\hline \multirow{2}{*}{ Base de dados } & \multirow{2}{*}{$\begin{array}{l}\text { Matrículas de } \\
\text { ingressantes }\end{array}$} & \multicolumn{4}{|c|}{ Matrículas de ingressantes localizadas no ENEM } \\
\hline & & ENEM 1 & ENEM 2 & ENEM 3 & ENEM 1,2 e 3 \\
\hline CES 2012 & 334.212 & $255.742(77 \%)$ & $148.664(44 \%)$ & - & $270.853(81 \%)$ \\
\hline CES 2013 & 325.267 & $260.809(80 \%)$ & $165.452(51 \%)$ & $92.822(29 \%)$ & $279.500(86 \%)$ \\
\hline CES 2014 & 346.991 & $282.060(81 \%)$ & $187.466(54 \%)$ & $115.872(33 \%)$ & $301.161(87 \%)$ \\
\hline CES 2015 & 336.093 & $286.607(85 \%)$ & $202.498(60 \%)$ & $128.645(38 \%)$ & $302.236(90 \%)$ \\
\hline
\end{tabular}

Fonte: CES/ENEM (INEP). Elaboração própria.

Ademais, a mesma tabela apresenta também os quantitativos e percentuais de matrículas encontradas na base de dados do ENEM juntando-se as diferentes edições (ENEM 1, 2 e 3), sempre priorizando o ENEM 1 sobre os demais. Desse conjunto de procedimentos, foi possível localizar de $81 \%$ a $90 \%$ das matrículas de ingressantes entre 2012 e 2015. É digno de nota reiterar que a maior parte desses valores, como vimos, decorrem dos percentuais de matrículas encontradas no ENEM 1, tendo o ENEM 2 ou 3 um papel meramente complementar.

Comparar a classificação racial dos ingressantes no CES e no ENEM, entre aqueles com declaração racial válida nos dois levantamentos, é fundamental para verificar o grau de concordância e discordância na declaração racial dos mesmos indivíduos, o que nos permite estimar possíveis vieses que a complementação de dados via ENEM traria ao CES. Para tanto, efetuamos também a comparação nas informações de sexo e mês 
de nascimento, aqui utilizados como "variáveis de controle" (tendo em vista que não se espera encontrar divergência na declaração desses dados). Em linhas gerais, a Tabela 3 apresenta o grau de concordância e discordância de sexo, mês de nascimento e cor/raça dos ingressantes de $2015^{12}$, em relação às três edições anteriores do ENEM.

Tabela 3 - Concordância e discordância (\%) de sexo, mês de nascimento e cor/raça de ingressantes dos cursos de graduação das IFES, entre CES 2015 e ENEM.

\begin{tabular}{c|c|c|c|c}
\hline Variável & Comparação & ENEM 2014 & ENEM 2013 & ENEM 2012 \\
\hline \multirow{2}{*}{ Sexo } & Discordância & 0,5 & 0,5 & 0,5 \\
& Concordância & 99,5 & 99,5 & 99,5 \\
Mês de Nascimento & Discordância & 0,2 & 0,1 & 0,2 \\
& Concordância & 99,8 & 99,9 & 99,8 \\
Cor/Raça & Discordância & 20,2 & 22,8 & 24,4 \\
& Concordância & 79,8 & 77,2 & 75,6 \\
\hline
\end{tabular}

Fonte: CES/ENEM (INEP). Elaboração própria.

Em sintese, nota-se que as concordâncias de sexo e mês de nascimento fixaram-se em valores superiores a 99\% dos ingressantes, independentemente da edição do ENEM considerada. Essa estabilidade aponta para elevada convergência entre os dados dos dois levantamentos no tocante a características individuais dos estudantes. Em contrapartida, o cenário é outro quando comparamos as declarações raciais dos ingressantes no CES 2015 com suas inscrições nas três edições anteriores do ENEM. Com relação ao ENEM 2014, vê-se um grau de concordância da declaração racial em 79,8\%, percentual que cai para $77,2 \%$ e para 75,6\%, respectivamente, nas duas edições prévias.

Não basta, porém, observar que existe discordância na classificação racial dos estudantes, se não apresentarmos em torno de quais cores ou raças essas divergências se concentram. Para tanto, comparamos, na Tabela 4, a declaração racial dos mesmos indivíduos entre o CES 2015 e o ENEM 1, 2 e 3 (priorizando a edição mais recente com declaração racial válida). Na tabulação cruzada abaixo, a diagonal sombreada ilustra a concordância racial entre os dois levantamentos, ao passo que todos os demais valores fora dessa diagonal indicam alguma discordância.

12- Em razão dos limites de espaço, focaremos nossas análises na edição mais recente do CES (i.e. 2015). 
Tabela 4 - Declaração racial (\%) dos ingressantes dos cursos de graduação das IFES no CES 2015 e ENEM.

\begin{tabular}{|c|c|c|c|c|c|c|c|}
\hline \multirow{2}{*}{\multicolumn{2}{|c|}{ Cor/Raça }} & \multicolumn{5}{|c|}{ ENEM 1,2 e 3} & \multirow{2}{*}{ Total } \\
\hline & & Branca & Preta & Parda & Amarela & Indígena & \\
\hline \multirow{5}{*}{ 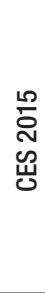 } & Branca & 39,4 & 0,4 & 4,7 & 0,5 & 0,0 & 45,1 \\
\hline & Preta & 0,5 & 7,4 & 3,4 & 0,0 & 0,0 & 11,3 \\
\hline & Parda & 5,0 & 3,3 & 31,9 & 0,6 & 0,2 & 41,0 \\
\hline & Amarela & 0,4 & 0,1 & 0,5 & 0,7 & 0,0 & 1,7 \\
\hline & Indígena & 0,1 & 0,1 & 0,3 & 0,0 & 0,3 & 0,8 \\
\hline \multicolumn{2}{|c|}{ Total } & 45,4 & 11,2 & 40,8 & 1,9 & 0,6 & 100,0 \\
\hline
\end{tabular}

Fonte: CES/ENEM (INEP). Elaboração própria.

Observa-se que, conforme apresentamos anteriormente, apesar de as discordâncias na classificação racial girarem em torno de um quinto dos respondentes, não se constata uma alteração da mesma magnitude no perfil racial dos estudantes, tendo em vista que existe certa compensação na declaração racial que parece conduzir a um equilíbrio dinâmico nas classificações raciais, sobretudo envolvendo brancos, pretos e pardos. Tomando os primeiros como exemplo, constatam-se percentuais de brancos da ordem de $45,1 \%$ no Censo e 45,4\% no ENEM - diferença que, mesmo diminuta, é ainda menor para pretos e pardos.

Na literatura, há razoável acúmulo de pesquisas que abordam as divergências entre as classificações raciais obtidas por metodologias distintas, quer seja cotejando auto e heterodeclaração, a declaração racial diante de perguntas abertas ou fechadas ou a influência de perguntas com alterações no enunciado (Cf. QUEIROZ, 2004; CARVALHO, 2005; ROCHA; ROSEMBERG, 2007; MUNIZ, 2012). No entanto, existe uma insuficiência de estudos que caracterizem as concordâncias ou discordâncias na classificação racial entre instrumentos auto e heteropreenchidos, talvez por suporem que essas distinções não justificariam alterações na composição racial dos respondentes.

A par disso, é importante reconhecer que as divergências observadas não se explicam, necessariamente, pelas diferenças quanto à metodologia de preenchimento dos instrumentos, e sim pelo fato de estarmos trabalhando com duas medidas sobre uma variável altamente sujeita a reinterpretações de ordem subjetiva - como nos recorda Osorio (2003, p. 35), "não é o instrumento de mensuração que é impreciso, mas o fenômeno ao qual se endereça, pois a definição da pertença racial varia circunstancialmente”.

\section{Subnotificação racial: uma recusa à declaração?}

Conforme mencionamos anteriormente, o CES dispõe de duas categorias de não declaração racial: "Não dispõe da informação" e "Não declarada" (2009-13) ou "Aluno não quis declarar a cor/raça” (2014-15). Em tese, a primeira referir-se-ia à ausência de dados 
raciais no cadastro de estudantes em dada instituição, ao passo que a segunda seria voltada aos respondentes que teriam recusado deliberadamente a declaração de seu pertencimento racial. Logo, se assumíssemos que as respostas a essa segunda categoria seriam, de fato, sustentadas por uma recusa à classificação racial, nossa complementação de dados do CES via ENEM deveria estar restrita às matrículas cuja cor/raça estivesse apresentada como "Não dispõe da informação", caso contrário, poderíamos estar ignorando o direito subjetivo dos estudantes de optar pela não declaração.

Procurando avançar sobre esse ponto, identificamos nas bases de dados do ENEM quem são os "não declarados" do Censo. Trocando em miúdos, procuramos caracterizar as matrículas cuja cor/raça foi apresentada como "Não declarada" no CES 2012-13 ou como "Aluno não quis declarar a cor/raça" no CES 2014-15. Caso a hipótese acima estivesse correta, boa parte dessas matrículas deveria igualmente estar não declarada no ENEM, haja vista que, no preenchimento do sistema de inscrição desse exame, o respondente tem a possibilidade de optar pela não atribuição de uma cor/raça, de forma autodeclarada e autopreenchida. Porém, o que vemos na Tabela 5 não confırma essa expectativa.

Tabela 5 - Quantidade (n) e percentual (\%) de matrículas sem declaração racial dos ingressantes dos cursos de graduação em IFES no CES, segundo a cor/raça no ENEM - 2012-2015.

\begin{tabular}{|c|c|c|c|c|c|c|c|c|}
\hline \multirow{2}{*}{ CES } & \multirow{2}{*}{$\begin{array}{c}\text { Não } \\
\text { declarados* }\end{array}$} & \multicolumn{6}{|c|}{ ENEM 1,2 e 3} & \multirow{2}{*}{ Total } \\
\hline & & Branca & Preta & Parda & Amarela & Indígena & Não declarada & \\
\hline \multirow{2}{*}{2012} & $\mathrm{n}$ & 33.296 & 5.460 & 15.846 & 1.346 & 241 & 1.677 & 57.866 \\
\hline & $\%$ & 57,5 & 9,4 & 27,4 & 2,3 & 0,4 & 2,9 & 100,0 \\
\hline \multirow{2}{*}{2013} & $\mathrm{n}$ & 35.975 & 6.472 & 18.726 & 1.356 & 312 & 1.343 & 64.184 \\
\hline & $\%$ & 56,0 & 10,1 & 29,2 & 2,1 & 0,5 & 2,1 & 100,0 \\
\hline \multirow{2}{*}{2014} & $\mathrm{n}$ & 50.907 & 9.419 & 36.123 & 2.188 & 461 & 1.938 & 101.036 \\
\hline & $\%$ & 50,4 & 9,3 & 35,8 & 2,2 & 0,5 & 1,9 & 100,0 \\
\hline \multirow{2}{*}{2015} & $\mathrm{n}$ & 37.290 & 7.016 & 22.711 & 1.467 & 407 & 1.291 & 70.182 \\
\hline & $\%$ & 53,1 & 10,0 & 32,4 & 2,1 & 0,6 & 1,8 & 100,0 \\
\hline
\end{tabular}

Fonte: CES/ENEM (INEP). Elaboração própria.

* Contabilizaram-se apenas as respostas à opção "Não declarada" (2012-13) ou "Aluno não quis declarar a cor/raça" (2014-15).

Importam apreender, desses dados, os percentuais de matrículas não declaradas do CES que permanecem como não declaradas no ENEM (coluna sombreada): dos estudantes sem declaração racial no Censo, apenas 2,9\%, em 2012, e 1,8\%, em 2015, recusaram classificar-se racialmente no ENEM. Esses dados corroboram a hipótese de Senkevics, Machado e Oliveira (2016) de que, em realidade, a maior parte da subnotificação do quesito cor/raça no Censo decorre da ausência de informações coletadas no âmbito das instituições educacionais, e não propriamente de uma recusa, por parte dos respondentes, em declarar seu pertencimento racial. Caso contrário, os percentuais de não declaração no ENEM, cujo questionário é autodeclarado e autopreenchido, deveriam ser consideravelmente maiores. 
Com isso, podemos afirmar que a complementação de dados raciais no CES via ENEM não deve se reter apenas aos percentuais de "Não dispõe da informação", como também aos percentuais de "Não declarada”|“Aluno não quis declarar a cor/raça”, haja vista que essas não têm servido, ao que tudo indica, como uma não declaração subjetiva, e sim como uma ausência de informação disfarçada de recusa à declaração racial. Em realidade, as evidências parecem sugerir que, quando questionados, os estudantes atribuem a si uma cor ou raça, de modo que viabilizar a declaração racial discente, em âmbito institucional, pode ser um caminho promissor para compreender o perfil racial da universidade brasileira.

\section{Complementação dos dados de cor ou raça}

Em seguida, cabe-nos investigar o grau de complementação de dados raciais do CES via ENEM, como proposto nesta pesquisa. Importa rememorar que essa complementação foi realizada apenas entre as matrículas de ingressantes dos cursos de graduação das IFES que não apresentavam uma cor ou raça declarada no próprio CES. Para esses estudantes que, como vimos, compõem percentuais bastante significativos do Censo, rastreamos sua cor ou raça na edição imediatamente anterior do ENEM (ENEM 1); na ausência de uma declaração racial nesta, voltamo-nos a mais uma edição do exame (ENEM 2); e, na persistência dessa ausência, mais uma (ENEM 3), no caso dos ingressantes de 2013 a 2015. Uma visão geral dos resultados obtidos pode ser encontrada no Gráfico 2.

Gráfico 2 - Taxas de declaração racial entre ingressantes dos cursos de graduação das IFES, de acordo com a complementação de dados raciais via ENEM - 2012-2015.

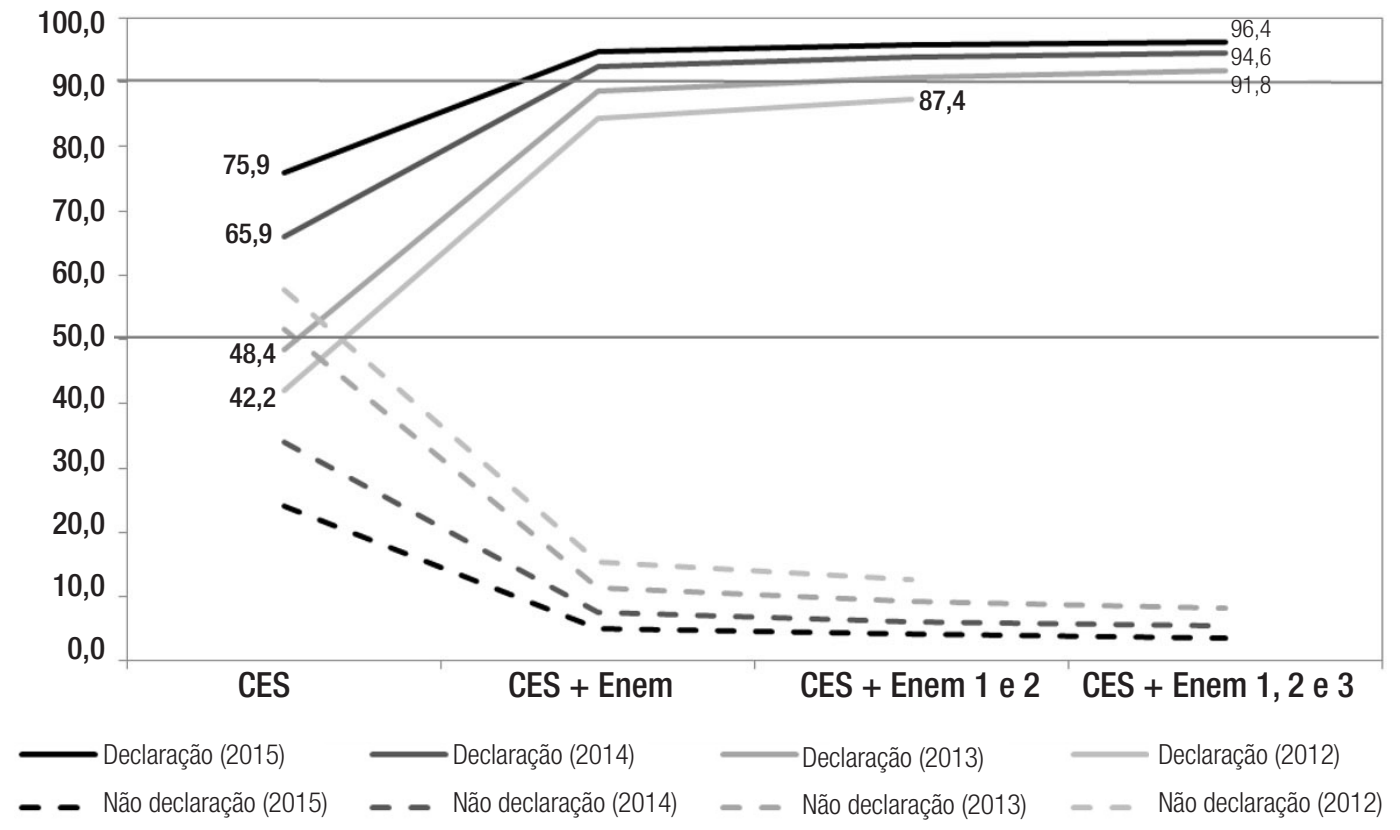

Fonte: CES/ENEM (INEP). Elaboração própria. 
Para interpretar essa figura, tomemos como exemplo a linha escura contínua, referente ao CES 2015. Quando se considera apenas as declarações raciais no CES, antes de efetuar a complementação de dados, tem-se uma taxa de declaração racial na ordem de 75,9\% das matrículas. Ao complementarmos essas declarações raciais com apenas uma edição do ENEM (CES + ENEM 1), passou-se a apresentar uma taxa de declaração racial de 94,9\%; com duas edições do ENEM (CES + ENEM 1 e 2), 95,9\%; e, finalmente, com três edições do ENEM (CES + ENEM 1, 2 e 3), chegou-se ao valor máximo de 96,4\%. Para as edições anteriores do Censo, passou-se de 65,9\% para 94,6\% no CES 2014; de 48,4\% para 91,8\% no CES 2013; e, por fim, de 42,2\% para 87,4\% no CES 2012.

É possivel tecer duas principais conclusões acerca dos incrementos realizados. Por um lado, quanto mais recente a edição do CES, maior a taxa de declaração racial obtida - tal resultado é esperado na medida em que as taxas de declaração racial das edições mais recentes já partem de patamares mais elevados; além do mais, quanto mais recente a edição do Censo, maior o percentual de matrículas localizadas nas bases do ENEM. Por outro lado, quanto mais anterior a edição do CES, maior a variação percentual entre as condições final e inicial. Esse fenômeno sugere que, justamente por ter se mostrado um procedimento bem-sucedido, a complementação de dados do CES via ENEM tende a impactar com mais força sobre as edições do Censo cuja obtenção de dados raciais é originalmente menos abrangente.

Para visualizarmos os efeitos dessa complementação de dados sobre a composição racial dos estudantes, a Tabela 6 apresenta as quantidades, os percentuais e os percentuais declarados dos ingressantes de 2015 nas condições inicial (CES 2015) e final (CES 2015 + ENEM 1, 2 e 3) da referida complementação ${ }^{13}$. Atesta-se um leve acréscimo de brancos (1,8 p.p.) e amarelos $(0,1$ p.p.) em detrimento de pretos (-0,2 p.p.) e pardos (-1,6 p.p.), se atentarmos para os percentuais válidos. Não obstante essas variações, é possível observar que tal procedimento não altera substancialmente o perfil dos ingressantes, indicando que, apesar de termos adicionado aproximadamente 20 p.p. no contingente com declaração racial, não foi introduzido um viés na composição racial dos estudantes, ao menos nesse nível de agregação.

Tabela 6 - Perfil racial das matrículas de ingressantes dos cursos de graduação em IFES, de acordo com a complementação de dados via ENEM - 2015.

\begin{tabular}{|c|c|c|c|c|c|c|}
\hline \multirow[b]{2}{*}{ Cor/Raça } & \multicolumn{3}{|c|}{ CES 2015} & \multicolumn{3}{|c|}{ CES 2015 + ENEM 1, 2 e 3} \\
\hline & Quantidade & Percentual & $\begin{array}{c}\text { Percentual } \\
\text { válido }\end{array}$ & Quantidade & Percentual & $\begin{array}{c}\text { Percentual } \\
\text { válido }\end{array}$ \\
\hline Branca & 116.818 & $34,8 \%$ & $45,8 \%$ & 154.108 & $45,9 \%$ & $47,6 \%$ \\
\hline Preta & 28.521 & $8,5 \%$ & $11,2 \%$ & 35.537 & $10,6 \%$ & $11,0 \%$ \\
\hline Parda & 102.746 & $30,6 \%$ & $40,3 \%$ & 125.457 & $37,3 \%$ & $38,7 \%$ \\
\hline Amarela & 4.403 & $1,3 \%$ & $1,7 \%$ & 5.870 & $1,7 \%$ & $1,8 \%$ \\
\hline Indígena & 2.540 & $0,8 \%$ & $1,0 \%$ & 2.947 & $0,9 \%$ & $0,9 \%$ \\
\hline Não declaração (total) & 81.065 & $24,1 \%$ & - & 12.174 & $3,6 \%$ & - \\
\hline Total & 336.093 & $100,0 \%$ & $100,0 \%$ & 336.093 & $100,0 \%$ & $100,0 \%$ \\
\hline
\end{tabular}

Fonte: CES/ENEM (INEP). Elaboração própria.

13- Para checar essa análise com edições anteriores do CES, ver Senkevics (2017). 
Explorando os resultados desse procedimento em maiores detalhes, a Tabela 7 compara a taxa de declaração racial das UFs antes e depois da utilização do ENEM para suplantar as não declarações de ingressantes das IFES. Vê-se que, em nenhum dos anos analisados, a taxa de declaração racial do CES + ENEM permaneceu em patamares inferiores a 50\%. Em 2014 e 2015, tampouco houve unidades federativas com declaração racial inferior a 80\%. No último ano, de apenas sete UFs com declaração racial superior a 95\%, passou-se para 20.

Tabela 7 - Quantidade de UFs segundo a taxa de declaração racial (em faixas) dos ingressantes de cursos de graduação em IFES - Brasil - 2012-2015.

\begin{tabular}{|c|c|c|c|c|c|c|c|c|}
\hline \multirow{2}{*}{$\begin{array}{c}\text { Taxa de Declaração Racial } \\
\text { das UFs }\end{array}$} & \multicolumn{2}{|c|}{2012} & \multicolumn{2}{|c|}{2013} & \multicolumn{2}{|c|}{2014} & \multicolumn{2}{|c|}{2015} \\
\hline & CES & $\begin{array}{l}\text { CES + } \\
\text { ENEM }\end{array}$ & CES & CES & CES & $\begin{array}{l}\text { CES + } \\
\text { ENEM }\end{array}$ & CES & $\begin{array}{l}\text { CES + } \\
\text { ENEM }\end{array}$ \\
\hline Até 50,0\% & 18 & 0 & 14 & 0 & 7 & 0 & 4 & 0 \\
\hline $50,1 \%$ a $80,0 \%$ & 4 & 4 & 8 & 3 & 9 & 0 & 5 & 0 \\
\hline $80,1 \%$ a $90,0 \%$ & 5 & 12 & 5 & 8 & 5 & 4 & 6 & 1 \\
\hline $90,1 \%$ a $95,0 \%$ & 0 & 6 & 0 & 8 & 5 & 10 & 5 & 6 \\
\hline $95,1 \%$ a $100,0 \%$ & 0 & 5 & 0 & 8 & 1 & 13 & 7 & 20 \\
\hline
\end{tabular}

Fonte: CES/ENEM (INEP). Elaboração própria.

Para visualizar os resultados da tabela acima de uma maneira mais ilustrativa, a página seguinte ilustra dois mapas da declaração racial relativos a 2015 (Cartograma 1), em que se compara a declaração racial, por UF, nas condições inicial e final da complementação de dados. A partir dos dados apresentados, nota-se que, ainda que persista um relativo mosaico na declaração racial das UFs dentro de uma mesma região, essa heterogeneidade tende a reduzir na condição final de complementação de dados, na medida em que o mapa se eleva para um patamar de maior declaração racial. É possível perceber que a representação gráfica, como um todo, escurece, ilustrando graficamente as tendências expostas na tabela acima.

\section{Uma análise das trincas Instituição-Curso-Turno}

Para finalizar as análises da complementação de dados raciais do CES via ENEM, consideraremos como unidade de análise, nesta seção, as trincas formadas por InstituiçãoCurso-Turno, isto é, as combinações existentes entre cada curso de graduação (presencial ou a distância), oferecido nos turnos disponíveis de cada IFES. Optamos por desenvolver tal análise em virtude de a Lei de Cotas regulamentar, explicitamente, que a reserva de vagas na graduação se aplica a todos os cursos e turnos das IFES vinculadas ao MEC. 
Cartograma 1 - Taxa de declaração racial no CES 2015 nas condições inicial (sup.) e final (inf.) da complementação de dados raciais via ENEM.
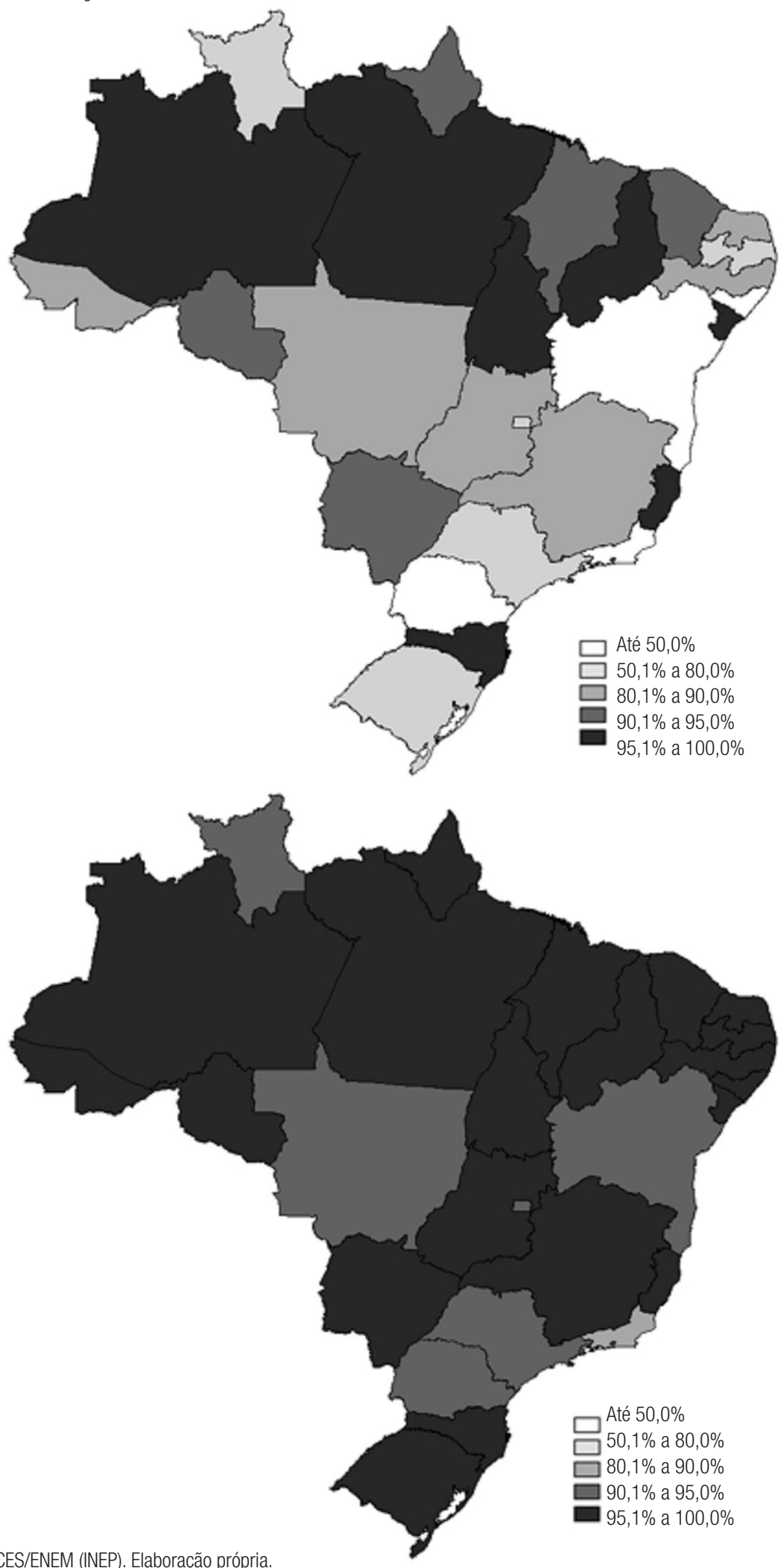
Com base nessa regra, observamos que, de acordo com a Tabela 8, há 6.250 trincas distintas pelo Brasil, concentradas nas regiões Nordeste e Sudeste, que, juntas, somam aproximadamente $60 \%$ das matrículas nessa categoria administrativa.

Tabela 8 - Quantidade (n) e percentual (\%) de trincas Instituição-Curso-Turno e de matrículas de ingressantes dos cursos de graduação em IFES, por Grande Região - 2015.

\begin{tabular}{ccccc}
\hline \multirow{2}{*}{ Grandes Regiões } & \multicolumn{2}{c}{ Trincas IFES-Curso-Turno } & \multicolumn{2}{c}{ Matrículas } \\
\cline { 2 - 5 } & $\mathbf{n}$ & $28,8 \%$ & $\mathbf{n}$ & $\%$ \\
\hline Nordeste & 1.797 & $11,9 \%$ & 98.773 & $29,4 \%$ \\
\hline Norte & 742 & $29,4 \%$ & 33.375 & $31,4 \%$ \\
\hline Sudeste & 1.837 & $10,1 \%$ & 61.157 & $18,2 \%$ \\
\hline Sul & 1.133 & $11,9 \%$ & 37.380 & $11,1 \%$ \\
\hline Centro-Oeste & 741 & $100,0 \%$ & 336.093 & $100,0 \%$ \\
\hline Total & 6.250 & & & 105 \\
\hline
\end{tabular}

Fonte: CES (INEP). Elaboração própria

É importante, pois, verificar quais são os percentuais de declaração racial nessa unidade de análise, uma vez que subsidiar o monitoramento da Lei de Cotas implica qualificar a informação de cor/raça para cada unidade de aplicação da referida legislação. Seguindo os procedimentos metodológicos desenvolvidos, obtivemos as taxas de declaração racial nas condições inicial e final de complementação de dados do CES via ENEM para cada trinca e, em seguida, ordenamos os percentis de declaração racial, ilustrados no Gráfico 3 tomando como exemplo os ingressantes de 2015.

Gráfico 3 - Percentis de declaração racial entre ingressantes de trincas Instituição-Curso-Turno, nas condições inicial (CES) e final (CES + ENEM) da complementação de dados raciais - 2015.

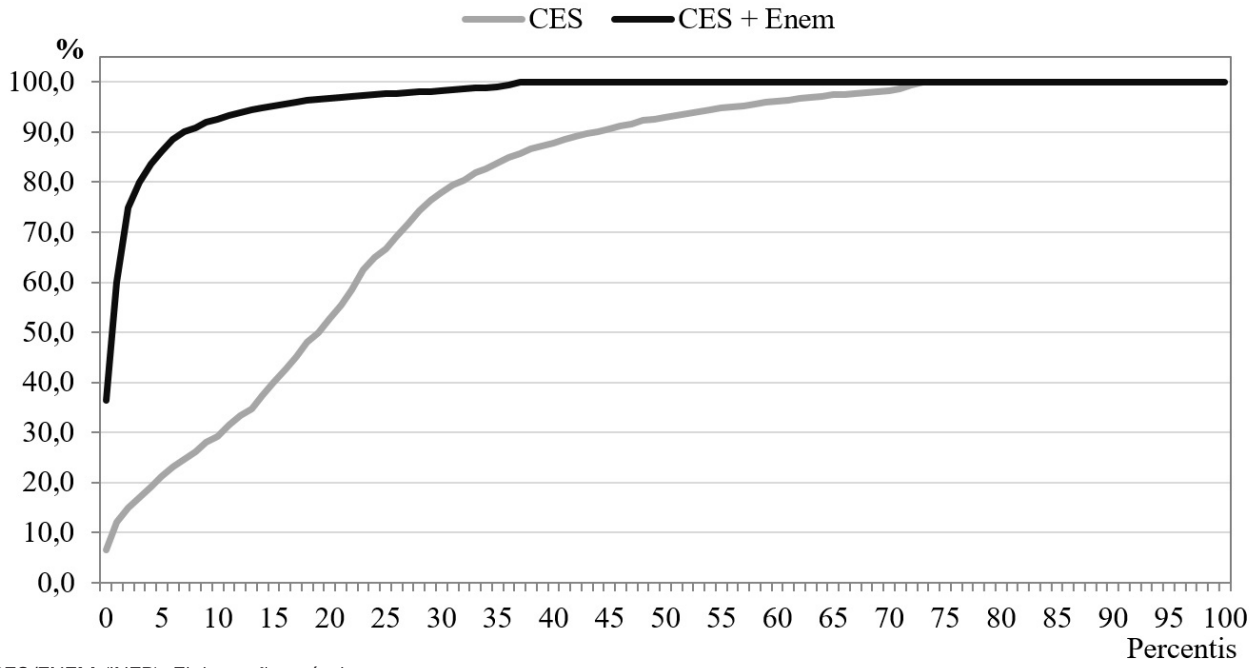

Fonte: CES/ENEM (INEP). Elaboração própria. 
Desses dados, apreende-se que, a depender das declarações raciais informadas pelas IFES, somente a partir do $74^{\circ}$ percentil alcançar-se-ia uma taxa de declaração racial equivalente a 100\% das matrículas, ao passo que tal valor é alcançado já no $38^{\circ}$ percentil quando se complementa com o ENEM. Isso significa dizer que houve um importante acréscimo de informação racial para o conjunto de trincas Instituição-Curso-Turno. Se, na condição inicial, 2.675 (42,8\%) trincas apresentavam taxas de declaração racial superiores a 95\% dos ingressantes, na condição final obteve-se 5.282 (84,5\%) trincas nessa faixa de declaração.

Porém, é preciso ter em mente que estamos tratando de uma unidade de análise que agrega um quantitativo diminuto de matrículas - apenas 8\% das trincas congregaram, em 2015, mais de 100 ingressantes em cada. Em razão disso, procedimentos metodológicos que, na esteira do que vimos desenvolvendo, adicionam informações em uma base de dados a partir de outra, podem introduzir vieses nas frequências relativas de cada categoria de cor ou raça. Assim, procuramos verificar qual foi o impacto da complementação dos dados raciais sobre as trincas no ano de 2015.

Para tanto, dicotomizamos a variável cor/raça entre brancos/amarelos e pretos/ pardos/indígena (PPI), em razão de os últimos serem os beneficiários da Lei de Cotas. Em seguida, calculamos a magnitude da variação percentual entre as frequências relativas de PPI, antes e depois da complementação de dados raciais, levando em conta o porte das trincas e suas respectivas taxas de declarações raciais iniciais ${ }^{14}$. Com isso, dimensionamos se trincas de menor porte e/ou com menor declaração racial inicial sofreriam maiores variações percentuais (Tabela 9).

Esses resultados indicam que, independentemente do porte das trincas, as variações percentuais entre as condições inicial e final da complementação de dados raciais tendem a ser menores quando as trincas já partem de coberturas raciais mais elevadas. Vê-se que, nas trincas com mais de 60 matrículas e taxas de declaração racial superiores a 50\%, cerca de dois terços delas observaram vieses nas proporções raciais inferiores a 1 p.p., contra apenas 5\% no caso de declarações iniciais de até 50\%. Mais do que o porte das trincas, o fator determinante por trás dos maiores ou menores vieses é a taxa de declaração racial inicial, conclusão que reforça a importância de as próprias instituições obterem, na origem, o perfil racial de seus ingressantes. Com isso, acréscimos na declaração racial por meio do ENEM tenderão a basicamente ampliar as frequências relativas de cor/raça para um contingente maior de ingressantes sem, no entanto, alterar substancialmente suas proporções originais.

\section{Considerações finais}

Por serem históricas e estruturantes da sociedade brasileira, as desigualdades sociais devem ser objeto de permanente intervenção, visando à reversão do quadro histórico de injustiças perpetradas contra parcelas expressivas da população brasileira. É nesse contexto que se inserem políticas universais e de ação afırmativa que almejam a ampliação

14- Para tanto, excluímos da análise trincas com menos de dez matrículas de ingressantes ou com taxa de declaração racial inicial igual a zero, com o intuito de minimizar vieses demasiadamente grandes. 
Tabela 9 - Quantidade (n) e percentual (\%) de trincas Instituição-Curso-Turno, segundo a magnitude da variação entre as condições inicial e final de complementação dos dados raciais - 2015.

\begin{tabular}{|c|c|c|c|c|}
\hline Porte & Tx. de Declaração Racial inicial & Variação percentual & $\mathrm{n}$ & $\%$ \\
\hline \multirow{8}{*}{ De 11 a 40 matrículas } & \multirow{4}{*}{ Até 50\% } & Menor de 1 p.p. & 23 & $7 \%$ \\
\hline & & Entre 1 e 5 p.p. & 59 & $17 \%$ \\
\hline & & Maior de 5 p.p. & 267 & $77 \%$ \\
\hline & & Total & 349 & $100 \%$ \\
\hline & \multirow{4}{*}{ Maior de $50 \%$} & Menor de 1 p.p. & 1.041 & $57 \%$ \\
\hline & & Entre 1 e 5 p.p. & 626 & $34 \%$ \\
\hline & & Maior de 5 p.p. & 156 & $9 \%$ \\
\hline & & Total & 1.823 & $100 \%$ \\
\hline \multirow{8}{*}{ De 41 a 60 matrículas } & \multirow{4}{*}{ Até 50\% } & Menor de 1 p.p. & 23 & $6 \%$ \\
\hline & & Entre 1 e 5 p.p. & 67 & $18 \%$ \\
\hline & & Maior de 5 p.p. & 287 & $76 \%$ \\
\hline & & Total & 377 & $100 \%$ \\
\hline & \multirow{4}{*}{ Maior de $50 \%$} & Menor de 1 p.p. & 891 & $59 \%$ \\
\hline & & Entre 1 e 5 p.p. & 541 & $36 \%$ \\
\hline & & Maior de 5 p.p. & 91 & $6 \%$ \\
\hline & & Total & 1.523 & $100 \%$ \\
\hline \multirow{8}{*}{ Acima de 60 matrículas } & \multirow{4}{*}{ Até 50\% } & Menor de 1 p.p. & 21 & $5 \%$ \\
\hline & & Entre 1 e 5 p.p. & 106 & $25 \%$ \\
\hline & & Maior de 5 p.p. & 299 & $70 \%$ \\
\hline & & Total & 426 & $100 \%$ \\
\hline & \multirow{4}{*}{ Maior de 50\% } & Menor de 1 p.p. & 824 & $63 \%$ \\
\hline & & Entre 1 e 5 p.p. & 391 & $30 \%$ \\
\hline & & Maior de 5 p.p. & 94 & $7 \%$ \\
\hline & & Total & 1.309 & $100 \%$ \\
\hline
\end{tabular}

Fonte: CES/ENEM (INEP). Elaboração própria.

de direitos à população, tais como a Lei $n^{\circ}$ 12.711/2012. Conforme temos defendido, o monitoramento e a avaliação dessa política pública são fundamentais para sua própria efetivação enquanto medida com potencial de transformar a realidade. Nesse contexto, importantes conclusões podem ser extraídas a partir deste estudo. 
Em primeiro lugar, é patente que o Estado brasileiro não dispõe, na atualidade, de ferramentas devidamente consolidadas para o acompanhamento, em nível nacional, da inclusão de negros e indígenas na Educação Superior, bem como dos demais públicos-alvo do sistema de reserva de vagas em instituições federais, do ingresso à conclusão. Como bem coloca Lazaro (2016, p. 153):

É preocupante que o monitoramento e a avaliação de política tão relevante seja esquecida. Não avaliar é o primeiro passo para desqualificar a política, ou, mais grave, atribuir aos beneficiários a responsabilidade por eventual fracasso em face de indicadores não conhecidos.

Por outro lado, dispomos, sim, de mecanismos que podem ser mobilizados para cobrir essas lacunas e, assim, conferir maior eficácia ao processo de monitoramento e avaliação da política em tela. Embora a proposta de complementar dados do CES via ENEM não seja propriamente nova, até então inexistia qualquer estudo que se aprofundasse nessa proposição.

Ao efetuarmos o cruzamento de bases de dados entre CES e ENEM, buscando rastrear e complementar informações sobre a cor ou raça dos ingressantes dos cursos de graduação das IFES, conseguimos localizar quantitativos elevados de matrículas de ingressantes no ENEM, o que sinalizava, de antemão, para a possibilidade de que esse cruzamento viesse a trazer informações relevantes para o estudo. De fato, os procedimentos realizados elevaram significativamente as taxas de declaração racial dos ingressantes nas quatro edições do Censo, sem que se alterasse substancialmente o perfil do contingente com declaração racial, isto é, não se acrescentou um viés que pudesse comprometer ou, ao menos, tornar questionáveis as operações realizadas. Mesmo quando se analisaram as combinações existentes de Instituição-Curso-Turno, foi possível observar que alterações substanciais nas frequências relativas dos grupos de cor/raça aconteceram, sobretudo, nas trincas que apresentavam patamares iniciais de declaração racial excepcionalmente baixos.

De toda forma, é importante tecer algumas ressalvas ao estudo. Ao complementar dados do CES via ENEM, estamos adicionando informações que foram coletadas por instrumentos distintos e que, apesar de o método de declaração racial ser o mesmo, estão situados em contextos diferentes, utilizam métodos de preenchimento distintos e são orientados para finalidades também distintas. Não é trivial, portanto, que dados de cor/ raça sejam acriticamente adicionados ao CES sem que essas ponderações sejam levadas em conta. Também é essencial mencionar que, no cenário ideal, o próprio Censo obteria informações de cor/raça com maior abrangência, sem que as técnicas aqui adotadas fossem necessárias; estas devem ser entendidas como uma medida paliativa para potencializar o monitoramento da Lei de Cotas no que tange à inclusão racial, e, portanto, como um recurso provisório.

É preciso, nas palavras de Guimarães (2016, p. 96, grifos do autor), “alterar os pressupostos da política racial brasileira”, isto é, superar o engodo histórico de que o Brasil é um país marcado por uma convivência harmoniosa entre as raças e por uma mestiçagem cuja existência mesma justificaria o silenciamento de eventuais conflitos. Ora, aprimorar as ferramentas de obtenção do perfil racial dos universitários significa, justamente, caminhar 
no sentido oposto a uma das narrativas fundantes da sociabilidade brasileira: implica desvelar as cores ou raças por trás das estatísticas educacionais e, assim, visibilizar as questões raciais como estratégia para enfrentar o racismo. De acordo com Carvalho (2006, p. 92), racismo esse que se expressaria não só pelas práticas discriminatórias no ambiente acadêmico, como também pela perpetuação do quadro até então vigente de inexistência de recenseamentos étnico-raciais nas universidades brasileiras, a qual termina por comprometer a superação do racismo porque, antes de mais nada, compromete a própria discussão sobre ele.

Esperamos, com esta iniciativa, contribuir para reforçar o debate em prol do enfrentamento das desigualdades raciais na educação brasileira, por meio de uma reflexão crítica e propositiva sobre as formas de monitoramento e avaliação de uma das mais importantes e indispensáveis políticas de ação afırmativa da atualidade.

\section{Referências}

ARTES, Amelia; RICOLDI, Arlene Martinez. Acesso de negros no ensino superior: o que mudou entre 2000 e 2010. Cadernos de Pesquisa, São Paulo, v. 45, n. 158, p. 858-881, 2015.

ARTES, Amelia. Desigualdades de cor/raça e sexo entre pessoas que frequentam e titulados na pósgraduação brasileira: 2000 e 2010. In: ARTES, Amelia; UNBEHAUM, Sandra; SILVÉRI0, Valter (Org.). Ações afirmativas no Brasil: reflexões e desafios para a pós-graduação. Cortez/Fundação Carlos Chagas, 2016. p. 19-59.

BRASIL. Congresso Nacional. Lei $\mathbf{n}^{\mathbf{0}}$ 12.711, de 29 de agosto de 2012. Dispõe sobre o ingresso nas universidades federais e nas instituições federais de ensino técnico de nível médio e dá outras providências, Brasília, DF, 29 ago. 2012. Disponível em: <http://www.planalto.gov.br/ccivil_03/_ato2011-2014/2012/ lei/l12711.htm>. Acesso em: 13 maio 2016.

CARVALHO, José Jorge de. Inclusão étnica e racial no Brasil: a questão das cotas no ensino superior. 2.ed. São Paulo: Attar, 2006. 211 p.

CARVALHO, Marília. Quem é negro, quem é branco: desempenho escolar e classificação racial de alunos. Revista Brasileira de Educação, Rio de Janeiro, n. 28, p. 77-95, 2005.

DAFLON, Veronica Toste; FERES JÚNIOR, João; CAMPOS, Luiz Augusto. Ações afirmativas raciais no ensino superior público brasileiro: um panorama analítico. Cadernos de Pesquisa, São Paulo, v. 43, n. 148, p. 302-327, 2013.

GUIMARÃES, Antonio Sérgio Alfredo. As cotas nas universidades públicas 20 anos depois. In: ARTES, Amelia; UNBEHAUM, Sandra; SILVÉRIO, Valter (Org.). Ações afirmativas no Brasil: reflexões e desafios para a pós-graduação. Cortez/Fundação Carlos Chagas, 2016. p. 93-124. 
HERINGER, Rosana. Ação afirmativa à brasileira: institucionalidade, sucessos e limites da inclusão de estudantes negros no ensino superior no Brasil (2001-2008). In: PAIVA, A. R. (Org.). Entre dados e fatos: ação afirmativa nas universidades públicas brasileiras. Rio de Janeiro: PUC-Rio/Pallas Ed., 2010. p. 117-144.

HONORATO, Gabriela. A distribuição de apoio social e atividades complementares entre estudantes das IFES por cor e condição de ingresso (cotista e não cotista). In: ARTES, Amelia; UNBEHAUM, Sandra; SILVÉRIO, Valter (Org.). Acesso e sucesso no ensino superior: uma sociologia dos estudantes. Rio de Janeiro: 7Letras/ Faperj, 2015. p. 142-162.

LAZARO, André. Observatório da Lei de Cotas: proposta de avaliação da Lei n. 12.711/2012. In: ARTES, Amelia; UNBEHAUM, Sandra; SILVÉRIO, Valter (Org.). Ações afirmativas no Brasil: reflexões e desafios para a pós-graduação. Cortez/Fundação Carlos Chagas, São Paulo, 2016. p. 125-156.

LIMA, Márcia; PRATES, Ian. Desigualdades raciais no Brasil: um desafio persistente. In: ARRETCHE, M. Trajetórias das desigualdades: como o Brasil mudou nos últimos cinquenta anos. São Paulo: Editora Unesp/ CEM, 2015. p. 163-189.

MOEHLECKE, Sabrina. Ação afirmativa no ensino superior: entre a excelência e a justiça racial. Educação \& Sociedade, Campinas, v. 25, n. 88, p. 757-776, 2004.

MUNIZ, Jeronimo 0. Preto no branco? Mensuração, relevância e concordância classificatória no país da incerteza racial. DAD0S - Revista de Ciências Sociais, Rio de Janeiro, v. 55, n. 1, p. 251-282, 2012.

OLIVEIRA, Jane Souto de. "Brasil mostra a tua cara": imagens da população brasileira nos censos demográficos de 1872 a 2000. Rio de Janeiro: Escola Nacional de Ciências Estatísticas, 2003. 75 p. (Textos para Discussão $n^{0}$ 6).

OSORIO, Rafael G. 0 sistema classificatório de "cor e raça" do IBGE. Rio de Janeiro: Ipea, 2003. 50 p. (Texto para Discussão no 996).

PETRUCCELLI, José Luis. Ethnic/racial statistics: Brazil and an overview of the Americas. In: FERRÁNDEZ, Luis Fernando Angosto; KRADOLFER, Sabine (Ed.). Everlasting countdowns: race, ethnicity and national censuses in Latin American states. Newcastle: Cambridge Scholars Publishing, 2012. p. 264-303.

PIOVESAN, Flavia. Ações afirmativas sob a perspectiva dos direitos humanos. In: SANTOS, Sales Augusto. Ações afirmativas e combate ao racismo nas Américas. Brasília: MEC/Secad, 2005. p. 33-43.

PIZA, Edith; ROSEMBERG, Fúlvia. Cor nos censos brasileiros. In: CARONE, I; BENTO, Maria Aparecida Silva. (Org.). Psicologia social do racismo: estudos sobre branquitude e branqueamento no Brasil. Petrópolis: Vozes, 2012. p. 91-120.

QUEIROZ, Delcele Mascarenhas Queiroz. Universidade e desigualdade: brancos e negros no ensino superior. Brasília: Liber Livros, 2004. 168 p.

RIBEIR0, Carlos Antônio Costa; SCHLEGEL, Rogério. Estratificação horizontal da Educação Superior no Brasil (1960 a 2010). In: ARRETCHE, Martaed. Trajetórias das Desigualdades: como o Brasil mudou nos últimos cinquenta anos. São Paulo: Editora Unesp/CEM, 2015. p. 133-162. 
ROCHA, Edmar José da; ROSEMBERG, Fúlvia. Autodeclaração de cor e/ou raça entre escolares paulistanos(as). Cadernos de Pesquisa, São Paulo, v. 37, n. 132, p. 759-799, 2007.

SANTOS, Sales Augusto dos. A Lei n 10.639/2003 como fruto da luta anti-racista do Movimento Negro. In: BRASIL. Ministério da Educação. Secretaria de Educação Continuada, Alfabetização e Diversidade. Educação anti-racista: caminhos abertos pela Lei Federal nº 10.639/03. Brasília: MEC/Secad, 2005. p. 21-37.

SENKEVICS, Adriano Souza; MACHADO, Taís de Sant'Anna; OLIVEIRA, Adolfo Samuel. A cor ou raça nas estatísticas educacionais: uma análise dos instrumentos de pesquisa do INEP. Brasília, DF: INEP, 2016. 48 p. (Texto para Discussão n 41).

SENKEVICS, Adriano Souza. Cor ou raça nas instituições federais de ensino superior: explorando propostas para o monitoramento da Lei de Cotas. Brasília, DF: INEP, 2017. 60 p. (Texto para Discussão; n. 42).

VIEIRA, Paulo Alberto dos Santos. Para além das cotas: contribuições sociológicas para o estudo das ações afirmativas nas universidades brasileiras. Jundiaí: Paco Editorial, 2016. 292 p.

Recebido em: 23.07.2017

Revisões em: 29.11.2017

Aprovado em: 06.12.2017

Adriano Souza Senkevics é pesquisador do Instituto Nacional de Estudos e Pesquisas Educacionais Anísio Teixeira (INEP), especialista em Gestão de Políticas Públicas em Gênero e Raça pela Universidade de Brasília (UnB), mestre e doutorando em Educação pela Universidade de São Paulo (USP). 